\title{
An Empirical Study on Reading Aloud and Learning English by the Use of the Reading Assistant SRS
}

\author{
https://doi.org/10.3991/ijet.v15i21.18193 \\ Jingjing Li \\ Xi'an International Studies University, Xi'an, China \\ lijingjing@xisu.edu.cn
}

\begin{abstract}
This paper investigates the English pronunciation skills and its integration with other language skills when adopting the computer-assisted curriculum design. And it further explores the effectiveness of the Speech Recognition System (SRS) that was incorporated into a traditional English pronunciation class in China. During the course of this study, English majors who completed the SRS procedure for one year were examined in discrete aspects for the relationship between their reading aloud proficiency and language proficiency. The results show that the experimental groups with the SRS reading system curriculum design showed great effectiveness in improving learners' reading aloud proficiency. As compared with traditional training methods for English oral reading, the computer-assisted form of oral training improved the students' listening, pronunciation, reading, and writing skills. The SRS system also was found to be conducive to enhancing students' interest in language learning and in cultivating their acceptance of self-directed learning.
\end{abstract}

Keywords - Reading aloud, Reading Assistant, SRS, CALL, language proficiency

\section{Introduction}

Well-established technologies, together with the use of personal computers, have become more and more popular in countries that study English as a foreign language (FL). In addition, relatively new technologies such as language learning software and smart phones have made the process of learning English more personal and flexible. In this study, English proficiency means an overall evaluation of a student's Englishspeaking ability in terms of grammar, vocabulary, pronunciation, and beyond. Reading aloud in a foreign language is an effective way to learn the language, and it has long been regarded as an effective learning method in Chinese language teaching. Wang [1] pointed out that reading aloud is not a simple mechanical act of pronunciation of discrete words. When reading aloud, the reader activates a detailed knowledge of the language including word collocation, sentence structure, cohesion, rhythm, speed, accent, and intonation patterns. In the process, this knowledge becomes practical and contributes to the integration of overall English proficiency. 


\section{$2 \quad$ Literature Review}

As our research investigates predictors of reading aloud ability when using learning software, it is important to briefly outline the status quo of reading aloud studies and the current trends in Computer-assisted Language Learning (CALL). Most studies on reading aloud have been conducted with children and young students who speak English as their mother tongue, and have focused on the relationship between students' reading aloudfluency and reading comprehension proficiency [2-5]. These studies were conducted in class using the reading aloud method, and the results have proved that reading aloud is an effective way to teach English reading and learning. One problem in this process, however, is that teachers tend to regard reading aloud as a kind of guided experience rather than allowing students to participate actively in this activity. For a definition of "reading aloud" as it is understood in China, the Chinese scholar Zhu in the Chinese Dictionary of Psychology defined it as "an integration of brain, eyes, and text into the oral reading process". In English academia, it typically means the process of readers using stress, rhythm, intonation, and other linguistic means to express the thoughts and feelings conveyed in language materials.

Because this research incorporates Speech Recognition System (SRS) software into reading aloud practice, it belongs to a sub-branch termed Computer-assisted Language Learning (CALL). Many scholars have proposed different categories of CALL (see EuroCALL* for the link to Graham Davies's website, 1991). Garrett [6] reviewed the model of pedagogical software - tutorials, drills, games, simulations, and problem solving - and believed that these models have become irrelevant in modern times, especially because CALL uses general consumer communication tools and applications for which the term pedagogical software is no longer applied. The current CALL can be classified in three categories: tutorials, engagement with authentic material, and communication. The Speech Recognition System for our class design was a mixture of tutorials and engagement with authentic material. Web-based materials also can be developed that provide not only learning guidelines, but also authentic materials for imitation with appropriate feedback. Indeed, lifelong learning depends largely on students' ability to engage with authentic materials in their personal areas of interest.

Compared with the traditional way of learning, a computer-assisted English learning system has more abundant modes of presentation that enable users to learn the language theory in entertaining ways. Learners also can complete the learning targets and tasks together with regular examinations and automatic paper inspection [7]. This has been a subject of investigation for over 30 years. Although the main focus of this study is on the effectiveness of the use of technology in FL learning, it lacks relevant data for the research design, offers a poor choice of variables to be investigated, and it bases it studies on untrained users of the technology. Meanwhile, Previous studies mainly have focused on European languages, especially English, and lacked a systematic approach to the study of FL learning [8-10]. In this regard, computer-assisted oral reading teaching has the following concerns: 
1. Proper introduction to the functionality of computer assistance and the use of computer software

2. Use of the computer to assist in English pronunciation testing

3. Computer-based analysis of pronunciation errors

To the best of our knowledge, no empirical data has as yet been collected on the actual pedagogical effectiveness of computer software in improving the quality of FL learning.

Poncela [11] invented a software tool for electronic learning, whereby it was proposed that the most important part of higher education - university classroom education - should have better tools and methods to guide teachers and learners in the construction of classroom content and in the provision of related learning tasks. Traditional CALL has several disadvantages such as the lack of adaptability, interaction skills, creativity, and error correction ability. Considering the rapid developments in the computer field and the many improvements to teaching requirements in colleges and universities, the traditional CALL model is therefore no longer suitable for classroom education in colleges and universities, especially in China. In China, the CALL studies were first introduced in the 1990s, and then educators started to learn how to integrate computers into their class designs. Several studies focused on the attitudes towards CALL - for example, by conducting quantitative studies using questionnaires, and by initiating studies focusing on the effectiveness and assessment of the computer software [12-14]. In this area of research, the cross-language, crosscurriculum, bilingual and trilingual study contexts need to be further investigated.

\section{Introduction to Reading Assistant}

Reading Assistant, an SRS developed by the American Scientific Learning Company, employs language learning theory to improve learners' pronunciation competence through imitation and reading aloud. In addition, it helps to develop language skills by integrating vocabulary and grammar. When using the system, students take a self-test based on benchmark articles with a default result. Each article is read aloud ten times. To achieve the fine goal of imitation, the system then imports the pronunciation practice. In actual communication activities, listening skills, speaking skills, reading skills, and writing skills do not imply an exchange of thoughts based on isolated factors and words, but rather based on synthetic statements and higher-level discourse units. Isolated factors and word pronunciations in the comprehensive application include many variations, such as linking, incomplete burst and weakening. The articles included in the system also support variations in the pronunciation ability of males and females of all ages.

Additionally, the system's intelligent automatic scoring function ensures the accuracy of pronunciation imitation, as well as the objectivity and controllability of the reading process. The reading aloud imitation of the students is evaluated for correctness in pronunciation, misreading, reading incapacity, inaccuracy, and is highlighted using different colors. When a serious error occurs during the reading imitation process, the system comes to a halt, randomly plays a correct pronunciation, and asks the 
practitioner to repeat it. In addition to the comprehensive assessment on the readaloud, students, after each reading, are also made aware of the speech rate, the error rate, and the phrases most frequently misread (as stored in the system memory). Tutors can at any time supervise students' processes of reading aloud to verbally point out reading problems. The system also includes reading exercises to train in vocabulary, discourse, and paragraph comprehension. While students are completing the readings, they also can-do other exercises for further language enhancement and to better comprehend the articles.

The design of this SRS is a good illustration of the activity theory as used in the design and construction of learning environments. It emphasizes the appropriateness of analyzing needs, tasks, and outcomes, as well as the interaction of human activity and consciousness within the relevant environmental context [15]. Research on the adoption of autonomous technology-based pronunciation learning shows the possibility of developing pronunciation autonomy [16]. Calvo-Benzies [17] proposed that in the traditional approaches to teaching pronunciation in class, the main focus is on the individual sounds (in this case, only segmental pronunciation was considered). Pronunciation tasks therefore were designed in decontextualized drills, whereas in more current approaches, the emphasis is expected to be placed on both segmental and supra-segmental tasks including aural-oral drills as well as (semi-) communicative practice formats.

Zheng et al. [18] proposed a system called Software Testing Computer Assistant Education (STCAE), which was based on, information retrieval, and natural language processing technology. Gao et al. [19] selected a sample group of 142 students from a university in Shanghai, China. Then, the difficulty level of the material to be read aloud was selected through the manual evaluations of different teachers, and all the data was annotated by trained raters. Results showed that the reading aloud ability of the students correlated to the listening, reading, and cloze skills evidenced in the English proficiency test. The authors pointed out that the main limitation of this research was the manual process of selection, evaluation, and annotation. To overcome these difficulties, computer-assistance may help researchers sort out the reading material and perform more rapid scoring and annotation. Reading aloud is a complex and multi-level procedure for FL learners encompassing all aspects of language skills. In general, the Reading Assistant SRS includes the most important features of modern approaches.

Based on this idea, Li [20] proposed a "Pronunciation Learning Cognition Model Based on Reading Assistant". Based on Li's model, learners apply the instruction resources to fulfill their learning tasks autonomously to achieve self-constructed knowledge of pronunciation through the support of the SRS auto-read system, faculty co-organization, and curriculum guidance, as well as through interaction between students, human-computer collaboration, and conversation. This provides a multielement, bi-directional instruction model composed of "teacher - student group instruction system - leading to ultimate knowledge construction". This design was applied to the present research.

From the literature review, it is obvious that there is a scarcity of studies that include a specific research design aimed at assessing the effectiveness of integrating 
software into the FL learning process. This study is unique in that it examines the effectiveness of a software-based model together with a specific curriculum design. In our study, which was conducted in the context of learning English as a foreign language in China, three main research questions were proposed:

1. What overall effect does the SRS reading system have on English reading aloud proficiency?

2. How does English reading aloud proficiency relate to English proficiency as a whole?

3. How do reading aloud proficiency, L2 proficiency, and other discrete skills interact with each other?

\section{$4 \quad$ Method}

The students participating in this study were all freshmen from the School of English Studies at Xi'an International Studies University, Xi'an, Shaanxi, China. They were informed about the aims and procedures of the study and asked for their consent. First, we randomly selected the experimental group and the control classes from 408 students with 28 students in each class; thus, 14 classes in total were formed. 116 students from four classes were selected. They were aged from 18 to 21 years old, and had learned English for 8-10 years. They were divided into two control classes and two experimental classes. All of them had passed the College Entrance Examination. The control classes followed the traditional teaching method, and the experimental classes adopted the Reading Assistant system as an extension to their ordinary class to train their English reading, listening, and related skills. Finally, an analysis of the correlation between reading aloud ability and English language proficiency was conducted, and open-ended questionnaires were distributed to enable students to further discuss the effect of Reading Assistant on their efforts and progress with self-directed learning.

\subsection{Instruments}

To assess the L2 language proficiency of the students, we chose the results of the College Entrance Examination, combined with the placement test designed by the School of English Studies at Xi'an International Studies University. We chose the average scores to sort the class into different groups, which is a standardized assessment tool designed by the Ministry of Education. To assess pre-reading proficiency, we randomly selected one passage from the SRS database, which automatically scored the reading aloud results. To assess the language proficiency after adopting the new learning model for a year, the proficiency test designed by the board of the School of English Studies was utilized to ensure post-test variability. The whole test design imitated the TEM 8 (Test for English Majors 8) examination. TEM 4 and TEM8 are large-scale English tests in China, which are held in April of the third year of study and in March of the fourth year of study, respectively. According to our re- 
search design, the language proficiency test was conducted at the end of the first year of study. Hence, we designed a quasi-TEM2 proficiency test for the participants. The test paper was proofread and pre-tested by TEM board members.

\subsection{Procedure}

The English placement test was administered during class hours and it lasted two hours. Students could access the listening part of the test only once. Trained research assistants supervised the administration of the tests. Then, all of the classes were sorted according to the placement test results and the College Entrance Examination tests. Four classes were randomly selected from the total of 14 classes. Then, the pre-reading aloud test was conducted in the computer lab. All participants took the test simultaneously. We used two hours to introduce them to the system, and each student was assigned their student ID as their account number. Initially, they worked by themselves to become familiar with each function including the different reading levels, the specific items of evaluation, and the recommended study material. Then, one hour was given to the participants for self-study, after which all the participants gathered again at the lab where the researchers had selected one passage from the system. All of the participants read the same passage at the same time. The researcher recorded the pre-reading aloud scores from the system. Subsequently, the two groups began their study for the whole year.

For the experimental groups, the SRS was incorporated with the design of their pronunciation course, and a trained teacher assisted them in the process. The experimental groups were asked to spend two hours per week in the language lab. During this time, they either presented their reading aloud results to their peers, or turned to the teachers to work out personal difficulties. For the remainder of the time, they used the SRS at their own volition. At the end of the first year, all the participants read again the same passage that they had read in the pre-test part. The participants then were assigned the proficiency test to examine whether or not their English proficiency had improved. Finally, questionnaires were distributed to the experimental group to further explore their feedback and to assess the potential benefits in their English learning. Fifty valid copies were retrieved. There were five questions in the questionnaire, and all of them were open-ended.

\section{$5 \quad$ Results and Discussion}

Two trained research assistants recorded the SRS reading aloud scores for the preand post-tests. SPSS was used for data analysis. Statistical procedures included computing descriptive statistics, and an independent sample t-test. Our first preliminary research question aimed to investigate differences for the students who used the SRS in their pronunciation class and the students who did not use it. 
Table 1. Independent samples t-test for reading aloud scores

\begin{tabular}{|l|c|c|c|c|}
\hline & t value & Two-tailed test (sig. 2-tailed) & \multicolumn{2}{c|}{ 95\% confidence interval } \\
\hline Pre-test & -1.391 & 0.167 & -8.19056 & 1.43194 \\
\hline Post-test & 4.764 & 0.000 & 7.63494 & 18.50299 \\
\hline
\end{tabular}

As shown in Table 1, during the pre-test, and prior to the use of Reading Assistant SRS in either class, the significance probability ( $p$-value $=0.167$ ) was above 0.05 , indicating that there was no significant difference in the performance of the two classes. In the post-test, the significant probability (p-value=0.000) was below 0.05 , which indicated a significant difference between the experimental and control classes.

The findings in Table 1 indicate that the SRS system significantly improves students' reading aloud proficiency. This finding corresponds to that of $\mathrm{Li}$ [20], who used this system in a traditional pronunciation teaching class and showed an improvement in the accuracy of the FL learners. The follow-up questionnaires show that the students thought that the SRS promoted their self-learning ability, and $68 \%$ of the students thought that they could arrange their own study plan under the guidance of the system.

Our second research question asks whether or not reading aloud systems have a positive effect on English proficiency as a whole. For this purpose, we calculated the correlation coefficients between the placement tests and the proficiency tests for the experimental class.

Table 2. Correlation coefficients between the placement test and proficiency test

\begin{tabular}{|l|c|c|}
\hline & Proficiency test & Placement test \\
\hline Pearson Correlation & 1 & $0.341^{* *}$ \\
\hline Sig. (2-tailed) & & 0.009 \\
\hline $\mathbf{N}$ & 58 & 58 \\
\hline Pearson Correlation & $0.341^{* *}$ & 1 \\
\hline Sig. (2-tailed) & 0.009 & \\
\hline $\mathbf{N}$ & 58 & 58 \\
\hline
\end{tabular}

${ }^{* *}$ Correlation is significant at the 0.01 level (2-tailed).

Table 3. Correlation coefficients between the oral reading performance scores, overall scores of performance test and the scores of each item

\begin{tabular}{|l|c|c|c|c|c|c|c|}
\hline & Proficiency T & Listening & Grammar & Cloze test & $\begin{array}{c}\text { Reading com- } \\
\text { pre-hension }\end{array}$ & Writing & $\begin{array}{c}\text { Error } \\
\text { correc-tion }\end{array}$ \\
\hline $\begin{array}{l}\text { SRS } \\
\text { score }\end{array}$ & $0.522^{* *}$ & $0.576^{* *}$ & 0.151 & 0.177 & $0.516^{* *}$ & $0.499^{* *}$ & 0.191 \\
\hline
\end{tabular}

As shown in Table 2, the Pearson's correlation coefficient was 0.341 between the proficiency test and placement test, while the level of significance reached 0.01 . These results show that the result of the reading aloud proficiency test was significantly related to the English proficiency test. Because we assumed that reading aloud proficiency exhibited a relationship with English proficiency, we conducted further 
analysis of the SRS reading score at the end of the first year by obtaining the correlation coefficients of the SRS scores with the proficiency test and its discrete items.

Table 3 shows that the SRS scores and the Proficiency T scores were significantly correlated. The highest correlation coefficient value was between the SRS score and the listening score $(\mathrm{r}=.576, \mathrm{p}<0.01)$. Moreover, the correlation coefficient was high between the SRS scores and the reading comprehension part $(\mathrm{r}=.516, \mathrm{p}<0.01)$. As for the other significantly related items, we found that writing ability was significantly correlated with reading aloud ability with a high value $(r=.499, \mathrm{p}<0.01)$. It can thus be hypothesized that reading aloud is another dimension of language output and an aspect of comprehensive language skills, while listening is an important method of input. These results correspond well with earlier studies that reading aloud helps students expand their auditory experiences with the target language, and thereby exposes them to words they usually would not hear. It is useful in helping the students become more familiar with the sound of words and phrases in order to perceive listening comprehension as less difficult [21, 22]. Nunan [23] emphasized that in the process of listening, the success of phoneme decoding depended largely on the mastery of stress, rhythm, and intonation. In the questionnaire part, $80 \%$ students praised the automatic scoring and correction adjustment function. In order to fit the scoring criteria and pass into the higher stage of learning, students had to imitate the pronunciations repeatedly, especially with regard to supra-segmental features such as stress, rhythm, and intonation.

Table 3 also shows that the reading scores were significantly correlated with reading comprehension and writing. As mentioned before, there were follow-up reading comprehension exercises after each reading aloud passage. These reading exercises included identification of the meaning of the words, thesis statements, and sentence paraphrasing in correspondence with the proficiency test. In addition, reading aloud is another way of input. Danks and Fears [24] proposed the "comprehension hypothesis", which suggests that oral pronunciation begins only after comprehension occurs (or at least after a semantic representation of the text has been constructed). Bowers' empirical study (1995) backed up this hypothesis with strong evidence. Hence, reading comprehension is the basis for - and an important aspect of - reading aloud. The SRS score can be correlated with four factors: The Proficiency T, listening comprehension, reading comprehension, and writing parts.

In pursuit of our third research question, we examined how the factors of Proficiency $\mathrm{T}$, listening comprehension, reading comprehension, and writing parts affect the SRS score. Table 4 indicates that the model primarily introduced the two factors of listening and reading. No variables were removed.

Table 4. Variables Entered/Removed

\begin{tabular}{|c|l|l|l|}
\hline $\begin{array}{c}\text { Mod- } \\
\text { el }\end{array}$ & Variables Entered & Variables Removed & \multicolumn{1}{c|}{ Method } \\
\hline 1 & Listening &. & $\begin{array}{l}\text { Stepwise (Criteria: Probability-of-F-to-enter }<=.050, \\
\text { Probability-of-F-to-remove }>=.100) .\end{array}$ \\
\hline 2 & Reading &. & $\begin{array}{l}\text { Stepwise (Criteria: Probability-of-F-to-enter }<=.050, \\
\text { Probability-of-F-to-remove }>=.100) .\end{array}$ \\
\hline
\end{tabular}


Table 5. Model Summary

\begin{tabular}{|c|c|c|c|c|c|}
\hline Model & R & R Square & Adjusted R Square & Std. Error of the Estimate & Durbin-Watson \\
\hline 1 & $0.908^{\mathrm{a}}$ & 0.825 & 0.822 & 4.66093 & \\
\hline 2 & $0.932^{\mathrm{b}}$ & 0.868 & 0.863 & 4.08820 & 1.910 \\
\hline
\end{tabular}

a. Predictors: (Constant), reading

b. Predictors: (Constant), reading, Listening

c. Dependent Variable: Proficiency T

Table 5 shows the model-fitting process. For the reading factor, the $\mathrm{R}$ value was 0.908 and the Adjusted $\mathrm{R}$ value was 0.822 . For the listening factor, the $\mathrm{R}$ value was 0.932 and the Adjusted R value was 0.868. The Durbin-Watson value was 1.910.

Table 6. ANOVA

\begin{tabular}{|c|l|c|c|c|c|c|}
\hline \multicolumn{2}{|c|}{ Model } & Sum of Squares & Df & Mean Square & F & Sig. \\
\hline \multirow{3}{*}{1} & Regression & 5364.441 & 1 & 5364.441 & 27.826 & $.000^{\mathrm{a}}$ \\
\cline { 2 - 7 } & Residual & 10795.904 & 56 & 192.784 & & \\
\cline { 2 - 7 } & Total & 16160.345 & 57 & & & \\
\hline \multirow{3}{*}{2} & Regression & 7088.058 & 2 & 3544.029 & 21.485 & $.000^{\mathrm{b}}$ \\
\cline { 2 - 7 } & Residual & 9072.286 & 55 & 164.951 & & \\
\cline { 2 - 8 } & Total & 16160.345 & 57 & & & \\
\hline
\end{tabular}

a. Predictors: (Constant), Listening

b. Predictors: (Constant), Listening, reading

c. Dependent Variable: SRS2

In Table 6, the F value is 21.485 (p-value < .005), which indicates that the SRS2 score has a linear relationship with listening and reading ability. This conclusion is also represented in Figures 1 and 2. 


\section{Histogram}

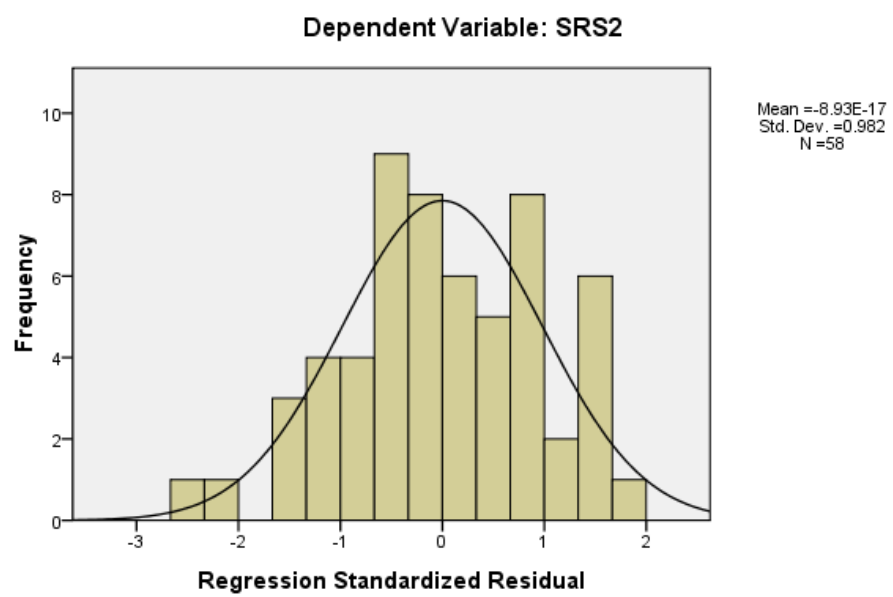

Fig. 1. Relationship between the SRS2 Scores and Listening and Reading Ability

Normal P-P Plot of Regression Standardized Residual

Dependent Variable: SRS2

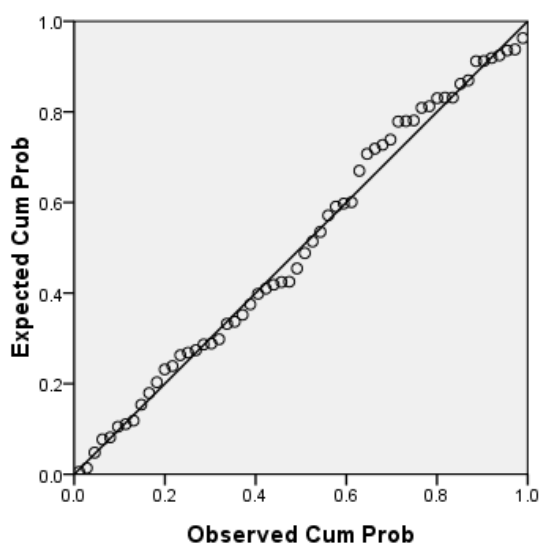

Fig. 2. Normal P-Plot of Regression Standardized Residual

Acquiring a high level of competence in pronunciation is a challenging task that all languages learners face; good pronunciation enhances speaking skills and also helps 
leaners become better listeners. Some studies show that certain linguistic features in L2 speech might affect comprehension and thus trigger more negotiation for meaning [25].

The results of Chinese speakers of English in this study also echoed the previous research results to show that L2 pronunciation ability appears to be related to reading comprehension and listening in depth. For example, previous studies of Japanese speakers of English, French speakers of English, and of second language speech production show that pronunciation is related to comprehensibility, and that this comprehensibility appears to be associated with segmental, prosodic, temporal, lexical, and grammatical aspects of L2 speech [26, 27].

With regard to the attitudes and experiences related to the inclusion of the SRS system in assisting the pronunciation class, 90\% students thought that they benefited from using the SRS system to assist in their learning, 94\% of the participants thought that it was very effective if incorporated into the traditional class together with the personalized study (as this system served as a diagnostic tool by detecting the difficulties in reading aloud, especially in the supra-segmental features). Chun et al. [28] claimed that the use of technology should neither be seen as a panacea, nor as a goal in and of itself, but rather as but one means to support specific learning goals. The results are in line with the Mahdi and Al Khateeb, [29] research result that the use of Computer Assisted Pronunciation Technology (CAPT) is more beneficial for university students, and that it could be more effective when pronunciation is presented inside rather than outside the classroom. Unlike the other language skills, pronunciation learning is a complex task; students struggle to learn by themselves, which can lead them to feel dependent on an instructor for regular feedback. Conventional teaching often relies on a teacher to model correct pronunciation and to evaluate and give feedback [30].

Among the 58 students, $80 \%$ were of the opinion that this learning model could be applied to the other classes that teach English skills. As to the question of the most interesting features or functions of Reading Assistant, $82 \%$ of the students thought that the articles in the system were interesting and useful, that they covered a wide range of topics, and that the web design was very attractive.

Hubbard and Siskin [31] proposed a flexible evaluation of both the experiences and expectations of the teachers and learners, among which the learners' fit was the focus of the study. Learners fit has been well illustrated in this course design, as $82 \%$ of them thought that besides pronunciation training, reading comprehension and vocabulary training were also of great importance, making the reading aloud segment an active part of the learning process rather than a mere training activity.

The last research question is concerned with the attitude of the participants towards the integration of the SRS into the course design of the pronunciation class, and if users view it as supplementary material only without tutoring. The results show that $73 \%$ of the students claimed the SRS together with the course design was better than working with it on their own. The students also were interested in the function of marking up different types of mistakes using colors during the course of reading aloud sessions [32-34]. 
Conventional training in oral reading was conducted manually, wherein the investigators selected different reading materials and the pronunciation teachers were invited to listen to the recordings of the students and identify their mistakes. In the SRS system, the students easily checked the types of mistakes marked in different colors. When they encountered difficulty in pronunciations that often did not fit the criteria set by the system itself, they preferred to turn to the tutor because the FL learners were not skillful enough to grasp the correct pronunciation based on native speakers, especially with regard to stress and rhythm. In such cases, they then had to turn to the tutors for face-to-face correction of each sound.

\section{Conclusion}

Our study results show that the SRS system was able to improve the reading aloud proficiency of students when incorporated into the pronunciation class. It also proved the application and effectiveness of Li's [20] model. Reading aloud proficiency was found to be closely related to the whole field of FL English proficiency, listening proficiency, reading comprehension proficiency, and writing abilities. The SRS scores exhibited a linear relationship with listening and reading ability, and assessed the language proficiencies of the FL learners. According to the learners' experience of SRS, they praised the SRS system for its contents, its assessment mechanism, and the whole class design in the English pronunciation class. In addition, all of the audio files in the SRS system were recorded by native speakers, so that the learners were immersed in a true native-speaking environment.

Technology provides new methods for language learning both for native speakers and foreign language learners. When teachers and learners use a technology purposefully and not merely for its own sake, it is found that they are able to engage in some degree of critical reflection. We are still trying to incorporate CALL into the other class designs. Because the SRS may have some effect on reading and listening skills, we are investigating a model for incorporating SRS into the curricula of other FL countries. With the development of communication technology, learners increasingly tend to show personal initiative and to actively reflect on their own communicative practice.

With computer software such as the SRS, it remains a critical question whether it is possible for FL learners to use the system independently and thereby to replace traditional pronunciation classes in FL learning environments. From their high school studies, college students generally come prepared with a basic knowledge of pronunciation. This pronunciation course, which was designed specifically for English majors in China, aims to improve students' accuracy and fluency in pronunciation. In our study, the learners praised the SRS's correction and assessment functions. However, to what extent the proper use of software will be able to replace the traditional class remains open for debate. We believe that reflection on these matters is the key to fostering the implementation of advanced learning software in the course designs of FL learning countries. 


\section{$7 \quad$ Acknowledgment}

We are obliged to The Department of education of Shaanxi Province for the support of our project: [Grant No.: 20JZ082], The China National Foundation for Social Sciences for the support of our project: [Grant No.:18BYY014], and this work was also supported by Xi'an International Studies University Postgraduate Research Project: [Grant No.: BSZA2019001].

\section{$8 \quad$ References}

[1] Wang, Z.Y. (2002). Reading aloud and English Learning. Foreign Languages and Their Teaching, 8(1610): 51-52. https://doi.org/10.13458/j.cnki.flatt.002500

[2] Cao, S., Liu, H. (2019). Effectiveness analysis of edmodo-based blended english learning mode, International Journal of Emerging Technologies in Learning, 14(18), 64-75. https:// doi.org/10.3991/ijet.v14i18.11184

[3] Fuchs, L.S., Fuchs, D., Maxwell, L. (1998). The validity of informal measures of reading comprehension, Remedial and Special Education, 9(2): 20-28. https://doi.org/10.1177/074 193258800900206

[4] Kearney, J. (2012). The study of second language acquisition: Rod Ellis. TESOL Quarterly, 29(3): 602-603. https://doi.org/10.2307/3588082

[5] Saienko, N., Olizko, Y., Arshad, M. (2019). Development of tasks with art elements for teaching engineers in english for specific purposes classroom, International Journal of Emerging Technologies in Learning, 14(23), 1955. https://doi.org/10.3991/ijet.v14i23.119 $\underline{55}$

[6] Garrett, N. (2009). Computer assisted language learning trends and issues revisited: Integrating innovation. The modern language journal, 93: 719-740. https://doi.org/10.1111/ j.1540-4781.2009.00969.x

[7] Bo, J., Wang, Y., Han, K. (2017). An English learning method based on computer-assisted system. International Journal of Emerging Technologies in Learning (iJET), 12(02): 66-77. https://doi.org/10.3991/ijet.v12i02.6045

[8] Felix, U. (2005). Analysing recent CALL effectiveness research-towards a common agenda. Computer assisted language learning, 18(1-2): 1-32. https://doi.org/10.1080/09588 $\underline{220500132274}$

[9] Stockwell, G. (2007). A review of technology choice for teaching language skills and areas in the CALL literature. ReCALL: The Journal of EUROCALL, 19(2): 105. https://doi.org/ $10.1017 /$ S0958344007000225

[10] Zheng, W., Bai, Y., Che, H. (2018). A computer-assisted instructional method based on machine learning in software testing class. Computer Applications in Engineering Education, 26(5): 1150-1158. https://doi.org/10.1002/cae.201962.

[11] Poncela, A. (2013). A web-based software educational tool for electronic instrumentation teaching. Computer Applications in Engineering Education, 21(S1): E62-E72. https://doi.o $\mathrm{rg} / 10.1002 / \mathrm{cae} .20564$

[12] Neri, A., Mich, O., Gerosa, M., Giuliani, D. (2008). The effectiveness of computer assisted pronunciation training for foreign language learning by children. Computer Assisted Language Learning, 21(5): 393-408. https://doi.org/10.1080/09588220802447651. 
[13] Tome Diez, M. (2015). Development, analysis and evaluation of oral production in foreign language class with new technologies. Theleme-Revista Complutense De Estudios Franceses, 30(2): 255-268. https://doi.org/10.5209/rev_THEL.2015.v30.n2.48663.

[14] Agarwal, C., Chakraborty, P. (2019). A review of tools and techniques for computer aided pronunciation training (CAPT) in English. Education and Information Technologies, 24(6): 3731-3743. https://doi.org/10.1007/s10639-019-09955-7.

[15] McCrocklin, S.M. (2016). Pronunciation learner autonomy: The potential of automatic speech recognition. System, 57: 25-42. https://doi.org/10.1016/j.system.2015.12.013

[16] Yunus, M.M., Salehi, H., Amini, M. (2016). EFL Teachers' Cognition of Teaching English Pronunciation Techniques: A Mixed-Method Approach. English Language Teaching, 9(2): 20-42. https://doi.org/10.5539/elt.v9n2p20.

[17] Calvo-Benzies, Y.J. (2017). English as a Lingua Franca (ELF) in ESP contexts. Students' attitudes towards non-native speech and analysis of teaching materials. Alicante Journal of English Studies, 30: 27-60. https://doi.org/10.14198/raei.2017.30.02.

[18] Zheng, H., Wang, J., Li, R., Yan, N. (2010). The review of English reading-aloud research in China, Journal of Yangtze University (Social Sciences), 33(2): 71-74.

[19] Gao, X., Yang, H.Z., Zhu, Z.C. (2006). Use of oral reading as an EFL testing task. Modern Foreign Languages, 29(4): 401-437.

[20] Li, J. (2018). English Pronunciation Curriculum Model on Reading Assistant SRS: Constructivism View. Educational Sciences: Theory \& Practice, 18(5): 1246-1254. https:// doi.org/10.12738/estp.2018.5.024.

[21] Allington, R. (1984). Oral Reading. In P. D. Person (Ed.), Handbook of Reading Research. London: Longman, 829-864.

[22] Eyseck, M. 1990. Cognitive Psychology. New York: Wiley.

[23] Nunan, D. (2001). Second language teaching and learning. Beijing: Foreign Language Teaching and Research Press.

[24] Danks, J.H., Fears, R. (1979). Oral reading: Does it reflect decoding or comprehension? In Resnick, L. B. \& Weaver, P. A. (Eds.), Theory and practice of early reading, 3: 89-108. Hillsdale, NJ: Erlbaum.

[25] Mackey, A., Gass, S., McDonough, K. (2000). How do learners perceive interactional feedback. Studies in second language acquisition, 22(4): 471-497. https://doi.org/10.1017/ $\underline{\text { S0272263100004010 }}$

[26] Isaacs, T., Trofimovich, P. (2012). "Deconstructing" comprehensibility: Identifying the linguistic influences on listeners' L2 comprehensibility rating. Studies in Second Language Acquisition, 34(3): 475-505. https://doi.org/10.1017/S0272263112000150

[27] Saito, K., Trofimovich, P., Isaacs, T. (2016). Second language speech production: Investigating linguistic correlates of comprehensibility and accentedness for learners at different ability levels. Applied Psycholinguistics, 37(2): 217-240. https://doi.org/10.107/S 0142716414000502.

[28] Chun, D., Kern, R., Smith, B. (2016). Technology in language use, language teaching, and language learning. The Modern Language Journal, 100(S1): 64-80. https://doi.org/10.1111/ modl.12302

[29] Mahdi, H.S., Al Khateeb, A.A. (2019). The effectiveness of computer-assisted pronunciation training: A meta-analysis. Review of Education, 7(3): 733-753. https://doi. org/10.1002/rev3.3165

[30] Baker, A. (2014). Exploring teachers' knowledge of second language pronunciation techniques: Teacher cognitions, observed classroom practices, and student perceptions. Tesol Quarterly, 48(1): 136-163. https://doi.org/10.1002/tesq.99 
[31] Hubbard, P., Siskin, C.B. (2004). Another look at tutorial CALL. ReCALL: The Journal of EUROCALL, 16(2): 448-461. https://doi.org/10.1017/S0958344004001326

[32] Garrett, N. (1987). A psycholinguistic perspective on grammar and CALL. In W. F. Smith (Ed.), Modern media in foreign language instruction: Theory and implementation, 169196. Lincolnwood, IL: National Textbook. https://doi.org/10.3138/cmlr.44.3.558

[33] Golonka, E.M., Bowles, A.R., Frank, V.M., Richardson, D.L., Freynik, S. (2014). Technologies for foreign language learning: a review of technology types and their effectiveness. Computer assisted language learning, 27(1): 70-105. https://doi.org/10.1080/ $\underline{09588221.2012 .700315}$.

[34] Griffin, S.M., Reading Aloud, TESOL Quarterly, 1992(4): 784-786.

\section{$9 \quad$ Author}

Jingjing $\mathbf{L i}$ is a $\mathrm{PhD}$ candidate of Xi' an International Studies University, associate professor in School of English Studies, Xi'an International Studies University. China. Her major fields of research are Applied Linguistics and language Learning.

Article submitted 2020-09-02. Resubmitted 2020-10-03. Final acceptance 2020-10-05. Final version published as submitted by the authors. 